\title{
Distribuição e leitura referencial de sujeitos nulos e plenos em línguas pro-drop e não pro- drop: evidências da natureza semi-pro-drop do português brasileiro
}

\section{Cláudia Roberta Tavares Silva}

Docente da Universidade Federal Rural de Pernambuco (UFRPE) e do Programa de PósGraduação em Letras da Universidade Federal de Pernambuco (UFPE).

Resumo: Um dos parâmetros que tem sido sobejamente investigado no quadro da gramática gerativa refere-se ao Parâmetro do Sujeito Nulo (cf. CHOMSKY, 1981; RIZZI, 1988, 1997, dentre outros), cuja fixação distingue línguas em que a posição sujeito é obrigatoriamente preenchida por um elemento realizado foneticamente (línguas não-pro-drop) (ex.: inglês e francês) de línguas em que essa posição pode ser ocupada por uma categoria pronominal não realizada foneticamente, nomeadamente pro (línguas pro-drop) (ex.: português europeu (PE) e italiano). Sob essa perspectiva de análise, a distinção entre esses dois tipos de línguas reflete a natureza binária do parâmetro. Não obstante, neste artigo, objetivo, a partir da análise descritiva a ser realizada entre o português brasileiro (PB) e as línguas supracitadas, apresentar evidências a favor da não-binaridade desse parâmetro, tendo em vista 0 PB comportar-se como uma língua semi-pro-drop (cf. COELHO et al., 2001; SILVA, 2004), resultado possivelmente do processo de mudança por que está passando sua gramática.

Palavras-chave: Parâmetro do Sujeito Nulo; distribuição dos sujeitos; leitura referencial; português
Abstract: Null subject parameter has been investigated in Generative Grammar a lot (cf. CHOMSKY, 1981; RIZZI, 1988, 1997, and others). The fixation of its value causes the distinction among languages: languages whose subject position is filled by a phonetically realized element (non-pro-drop languages, for example: English and French) and languages whose position can be filled by null pronominal element, namely pro (pro-drop languages, for example: European Portuguese (EP) and Italian). Based on this framework, the distinction among these languages reflects the binary nature of the parameter. However, in this paper, I intend to development a descriptive analysis between Brazilian Portuguese $(\mathrm{BP})$ and the languages that were mentioned in order to show the non-binarity of this parameter. Because BP has gone through a process of change in its grammar, it can be considered a semi-pro-drop language (cf. COELHO et al, 2001; SILVA, 2004).

Key Words: Null subject parameter; distribution of subjects; referential reading, Portuguese. 



\section{Introdução}

Assumindo com Rizzi $(1988,1997)$ que a fixação positiva do valor do Parâmetro do Sujeito Nulo por uma língua cuja posição pré-verbal do sujeito pode ser ocupada, sempre que possível, por pronomes referenciais foneticamente nulos (Princípio Evite Pronome (Cf. CHOMSKY, 1981)) tem a ver com a morfologia de flexão verbal rica no que concerne às especificações gramaticais fornecidas pelos morfemas a cada pessoa do paradigma flexional nessa língua, adotarei a análise de Galves (2001) que mostra o enfraquecimento morfológico (AGR) do PB em virtude de o seu paradigma de flexão verbal apresentar duas formas zero relativas à segunda pessoa do singular e à segunda pessoa do plural, ao contrário do $\mathrm{PE}$, que só apresenta uma forma zero na segunda pessoa do plural. Para tanto, vejam-se os paradigmas analisados pela autora: ${ }^{1}$

(1) $P B$ : eu canto, você/ ele canta, nós cantamos, vocês/ eles cantam

$P E$ : eu canto, tu cantas, você/ele canta, nós cantamos, vocês/eles cantam

(GALVES, 2001, p. 103)

Em virtude de o AGR em PB ser fraco em comparação ao do PE, implica dizer que sujeitos nulos referenciais são bastante produtivos nessa última língua, uma predição que é confirmada nos resultados quantitativos obtidos por Duarte (2000). Essa autora verifica que no $\mathrm{PB}$ há uma freqüência substancial do preenchimento da posição pré-verbal do sujeito com pronomes plenos, ao contrário do $\mathrm{PE}$ : primeira pessoa (74\% (PB)), 35\% (PE)); segunda pessoa (90\% (PB), 24\% $(\mathrm{PE}))$, e terceira pessoa $(58 \%(\mathrm{~PB}))$ e $21 \%(\mathrm{PE})) .^{2}$ Ao longo de sete períodos da história, a autora observa que o PB está sofrendo um processo de mudança paramétrica no que concerne à fixação dos valores do Parâmetro do Sujeito Nulo, deixando de ser uma língua pro-drop para ser uma 
3 " [...] the results attempting to trace the course of a parametric change in progress in Brazilian Portuguese $(\mathrm{PB})$, which is evolving from a null to a non-null subject language."

(DUARTE, 2000, p. 17)

${ }^{4}$ Cf. também Rizzi (1988), Duarte (2000) e Galves (2001) para uma conclusão similar. língua não-pro-drop ${ }^{3}$, conforme evidenciam os resultados percentuais relativos à presença de sujeitos pronominais plenos: 1845 (20\%), 1882 (23\%), 1918 (25\%), 1937 (46\%), 1955 (50\%), 1975 (67\%) e 1992 (74\%).

Gonçalves (1994), ao analisar o Parâmetro do Sujeito Nulo na gramática do PE, argumenta que as estruturas frásicas com sujeitos nulos referenciais correspondem ao caso não-marcado nessa língua. Em se tratando de sujeitos preenchidos, a autora verifica que estão submetidos à seguinte restrição: quando licenciados, recebem uma certa ênfase ${ }^{4}$, geralmente, uma leitura contrastiva que os opõe a outros sujeitos pragmaticamente possíveis no domínio do discurso. Disso resulta a formulação da seguinte predição: “[...] a omissão do sujeito não é opcional em português (grifo da autora da citação). [...] De alguma forma, o sujeito pronominal com matriz fonética é enfatizado." (Ibid., p. 161). Contrariamente ao $\mathrm{PE}$, no $\mathrm{PB}$ os sujeitos preenchidos não estão submetidos a essa restrição.

Vale referir ainda que, a partir do enfraquecimento de $A G R$ na gramática do $P B$, têm surgido diferenças substanciais entre ela e a do PE no que concerne à distribuição das categorias plenas e nulas em posição sujeito.

Uma das diferenças tem a ver com as estruturas de duplicação dos sujeitos, em que o DP sujeito é retomado por um pronome resumptivo. Segundo Costa e Galves (2002), essas estruturas são muito produtivas em PB, mas consideradas marginais e até agramaticais no PE em certos contextos:

(2) a. A Clarinha $a_{i}$ ela $a_{i}$ cozinha que é uma maravilha. (??PE OKPB)

b. Eu acho que o povo brasileiro $_{i}$ ele $_{i}$ tem uma grave doença. ( $\left.{ }^{*} \mathrm{PE} \mathrm{OKPB}\right)$

De acordo com Duarte (2000, p. 27), a emergência dessas construções evidencia que o PB está caminhando 
para se tornar uma língua não-pro-drop, como o francês, tendo como conseqüência a perda do Princípio Evite Pronome. Segundo Galves, é no "[n]ível das propriedades referenciais da flexão que existe uma diferença entre o PB e o PE", haja vista que o pronome lembrete comumente presente na posição sujeito em $\mathrm{PB}$ é "uma realização própria da concordância” no núcleo I e uma estratégia para "restabelecer os traços pronominais que asseguram a determinação"(GALVES, 2001, p. 50). ${ }^{5}$

Um outro contexto estrutural tem a ver com a interpretação da categoria vazia em posição de sujeito. Segundo Galves, "[a] interpretação determinada ou indeterminada do sujeito nulo em $\mathrm{PB}$ depende do contexto" (Ibid., p. 48). Assim, na oração encaixada, a seguir, a categoria vazia $(\mathrm{cv})$ em $\mathrm{PB}$ só pode ser coreferente do DP João; no PE, por outro lado, essa categoria pode ser co-referente a esse DP ou não:

(3) João disse que cv viria.

Assim, o enfraquecimento da morfologia de flexão verbal na gramática do $\mathrm{PB}$, em particular, no que se refere à defectividade do traço de pessoa ligado à flexão de terceira pessoa, tem evidenciado que "AGR, pelo menos na terceira pessoa do singular, parece ser referencialmente pobre demais para identificar um sujeito nulo como um pronome nulo específico." (GALVES, 2001, p. 110).

Partindo, portanto, da reorganização gramatical por que passa o $\mathrm{PB}$, serão descritas em diferentes contextos estruturais a distribuição de sujeitos nulos e plenos, bem como sua interpretação referencial, tomando por base que essa interpretação encontra-se submetida a esses contextos, o que implica dizer que não há opcionalidade na estrutura frásica concernente à presença ou ausência de sujeitos plenos, uma predição que vai ao encontro do que é proposto por Gonçalves (1994) para o PE, o inglês e o francês. Para tanto, este estudo, a partir da
${ }^{5}$ Para uma análise adicional das estruturas de duplicação dos sujeitos em $\mathrm{PB}$, conferir Silva (2004). 
${ }^{6}$ A seleção desses contextos e a análise desenvolvida para o PE, o francês e o inglês baseiam-se em Gonçalves (1994). Quanto às estruturas descritas para o $\mathrm{PB}$, são resultados de minha intuição como falante nativa. ampliação dos dados dessa autora com os dados do PB, tem por finalidade precípua desenvolver uma análise interlingüística baseada na sintaxe comparativa, a partir da qual será possível problematizar acerca da hipótese da binaridade do Parâmetro do Sujeito Nulo.

\section{Os dados interlinguísticos: por uma análise não-unificada}

Tem sido defendido que a realização de sujeitos nulos ou plenos não é opcional em línguas pro-drop por estar submetida a dadas restrições. Em línguas não-pro-drop que, à primeira vista, não licenciariam sujeitos nulos, esses sujeitos são obrigatórios em alguns contextos estruturais das línguas pro-drop, por exemplo: contextos de orações coordenadas e orações gerundivas adverbiais, segundo observa Gonçalves (1994). Dito isso, realizo, a seguir, uma análise descritiva de alguns contextos estruturais a partir dos quais estabeleço comparação entre o PB, o PE, o inglês e o francês ${ }^{6}$, a fim de apresentar evidências a favor da natureza semi-prodrop da primeira língua.

\subsection{Contextos de orações coordenadas}

Antes de iniciar a análise dos contextos estruturais das orações coordenadas, em que é possível a ocorrência de pronomes realizados foneticamente ou não, vale dizer que adoto a análise de Gonçalves (1994), segundo a qual, nessas estruturas, não ocorre coordenação de VPs, mas de orações (cf. também MATOS, 2003). Nessa acepção, o argumento que ocupa a posição de sujeito é selecionado semanticamente por seu respectivo predicador, não violando assim o Critério- $\theta$. Caso os VPs estivessem coordenados, o sujeito da oração coordenada corresponderia ao sujeito da oração coordenante, podendo receber dois papéis- $\theta$ distintos simultaneamente, atribuídos composicionalmente pelo verbo e seus complementos, uma análise que infringe a condição imposta pelo Critério- $\theta$. 
Ademais, Gonçalves verifica que no $\mathrm{PE}$ a não realização fonética do sujeito (representado pela categoria vazia e) é obrigatória na oração coordenada quando ele é co-referente com o sujeito de terceira pessoa da oração coordenante (cf. (4)). Contudo, sendo a referência disjunta, quando os sujeitos das duas orações são de terceira pessoa, a realização fonética do sujeito é obrigatória (cf. (5)):

(4) a.O mecânico arranjou o pneu e $e_{i} /{ }^{*}{ }_{j}$ foi-se embora.

b.O João ${ }_{i}$ viu o Pedro no cinema, mas $e_{i}{ }^{*}{ }_{j}$ não lhe falou.

(5) a.O mecânico ${ }_{i}$ arranjou o pneu e ele ${ }_{i}^{*} /$ foi-se embora.

b.O João ${ }_{i}$ viu o Pedro ${ }_{j}$ no cinema, mas ele ${ }_{i}^{*} /$ não lhe falou.

Fazendo agora uma análise comparativa das estruturas acima com as do inglês, do francês e do PB, observo que elas se comportam de forma similar ao PE quando existe a categoria vazia. Contudo, sendo o sujeito realizado foneticamente na oração coordenada, ele pode ter leitura co-referente ou disjunta, ao contrário do PE, que só admite a segunda leitura:

(6) Inglês:

a. John ${ }_{\mathrm{i}}$ saw Peter ${ }_{\mathrm{j}}$ at the cinema but $\mathrm{e}_{\mathrm{i}} /{ }_{\mathrm{k}}$ didn't talk to him.

"O João viu o Pedro no cinema, mas não falou com ele."

a'. John ${ }_{i}$ saw Peter ${ }_{j}$ at the cinema but he ${ }_{i} /$ didn't talk to him.

"O João viu o Pedro no cinema, mas ele não falou com ele."

(7) Francês:

a. Jean ${ }_{\mathrm{i}}$ a vu Pierre $\mathrm{j}_{\mathrm{j}}$ au cinéma, mais $\mathrm{e}_{\mathrm{i}} /{ }^{\mathrm{r}} \mathrm{j}$ ne lui a pas parlé.

"O João viu o Pedro no cinema, mas não falou com ele."

a'. Jean ${ }_{\mathrm{i}}$ a vu Pierre $\mathrm{j}_{\mathrm{j}}$ au cinéma, mais $\mathrm{il}_{\mathrm{i} / \mathrm{j}}$ ne lui a pas parlé. 
"O João viu o Pedro no cinema, mas ele não falou com ele."

a". Jean ${ }_{\mathrm{i}}$ a vu Pierre ${ }_{j}$ au cinéma, mais celui-ci ${ }_{i} / \mathrm{j}$ ne lui a pas parlé.

"O João viu o Pedro no cinema, mas este não falou com ele."

(8) Português Brasileiro:

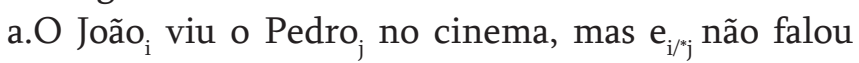
com ele.

a'.O João ${ }_{i}$ viu o Pedro ${ }_{j}$ no cinema, mas ele $e_{i j j}$ não falou com ele.

Em suma, observo que um ponto de similaridade entre as línguas estudadas é que, sendo o pronome foneticamente nulo, a leitura co-referente do sujeito da oração coordenada com o sujeito da oração coordenante é obrigatória. Não obstante, o locus de contraste entre o $\mathrm{PE}$, por um lado, e o inglês, o francês e o PB, por outro, dá-se quando o DP sujeito da oração coordenada é foneticamente realizado.

\subsection{Contextos de orações subordinadas finitas completivas ou adverbiais}

Ao contrário do que ocorre nas estruturas coordenadas em (4a) e (4b), em que o sujeito não realizado foneticamente recebe obrigatoriamente leitura co-referencial com o sujeito da oração coordenante, Gonçalves (1994) observa um contraste dessas estruturas com as estruturas subordinadas finitas completivas ou adverbiais, nas quais as leituras co-referente e disjunta estão disponíveis no $\mathrm{PE}$ ao pronome realizado foneticamente ou não na oração subordinada:

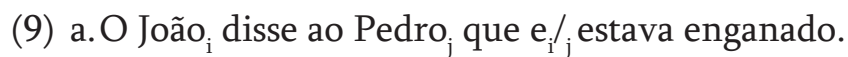
a'.O João disse ao Pedro que ele $_{i} /{ }_{j}$ estava enganado. b.Quando $e_{i} /$ ? ?j entrou, a Luísa ${ }_{\mathrm{i}}$ pareceu-me contente.

b'.Quando ela $a_{? i} /$; chegou a casa, a Ana foi fazer o jantar. 
Em se tratando dos contextos em (9), já se ergue uma distinção entre o PB, por um lado, e o inglês e o francês, por outro. Nessas últimas línguas, a realização fonética do sujeito na oração subordinada, que pode ter leitura co-referente ou disjunta com o sujeito da oração principal, é obrigatória, ao contrário do $\mathrm{PB}$, que pode ter ou o pronome não realizado foneticamente, sendo a leitura co-referente agramatical com o objeto indireto, ao contrário do $\mathrm{PE}$, ou o pronome realizado foneticamente, sendo sua leitura disjunta ou co-referente com o sujeito da oração principal à semelhança do $\mathrm{PE}^{7}$ :

(10) Inglês:

a. ${ }^{*}{ }{ } h_{n}$ told Peter ${ }_{j}$ that $e_{i} / j$ was very ill.

"O João disse ao Pedro que estava muito doente."

a'. John ${ }_{i}$ told Peter ${ }_{j}$ that he $e_{i} / j_{j}$ was very ill.

"O João disse ao Pedro que ele estava muito doente."

${ }^{7}$ Cf. também Galves (2001) para uma conclusão similar.

b. "When $\mathrm{e}_{\mathrm{i}} / \mathrm{j}$ got home, Ann $_{\mathrm{i}}$ started to prepare the souper.

"Quando chegou a casa, Ana começou a preparar a sopa."

$b^{\prime}$. When she ${ }_{i}$ jgot home, $A n n_{i}$ started to prepare the souper.

"Quando ela chegou a casa, Ana começou a preparar a sopa."

Francês:

a. ${ }^{*} \operatorname{Jean}_{\mathrm{i}}$ a dit à Pierre $\mathrm{j}_{\mathrm{j}} \mathrm{u}^{\prime} \mathrm{e}_{\mathrm{i}} / \mathrm{j}$ était très malade.

"O João disse ao Pedro que estava muito doente."

$a^{\prime}$. Jean ${ }_{i}$ a dit à Pierre ${ }_{j} q u e{ }^{\prime} i_{i} / j_{j}$ était très malade.

"O João disse ao Pedro que ele estava muito doente."

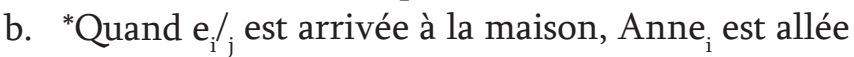
préparer le dîner.

"Quando chegou a casa, Ana começou a preparar o jantar."

b'. Quand elle / est arrivée à la maison, Anne ${ }_{i}$ est allée préparer le dîner.

"Quando ela chegou a casa, Ana começou a preparar o jantar." 
${ }^{8}$ Cf. também Huang (1989) para o chinês.
Português Brasileiro:

a. O João ${ }_{i}$ disse ao Pedro ${ }_{j}$ que $e_{i}{ }^{*}{ }_{j}$ estava muito doente.

a'. O João ${ }_{i}$ disse ao Pedro ${ }_{j}$ que ele $_{i^{\prime} j}$ estava muito doente.

b. Quando e $\mathrm{i}_{\mathrm{i}}$ ?? chegou em casa, a Ana $_{\mathrm{i}}$ começou a preparar o jantar.

b'. Quando ela ${ }_{i} / \mathrm{j}$ chegou em casa, a Ana $_{\mathrm{i}}$ começou a preparar o jantar.

Conforme observado na frase (b) do PB acima, a leitura co-referente do sujeito nulo da oração adverbial finita com o sujeito da oração principal é preferível ao invés da leitura disjunta. À semelhança do PE, essa última leitura só está disponível ao sujeito não realizado foneticamente caso haja um antecedente já introduzido no domínio do discurso com o qual a categoria vazia encontra-se ligada. ${ }^{8}$ Veja-se, portanto, o exemplo, a seguir, extraído de Mateus et al. (1989, p. 328 apud GONÇALVES, 1994, p. 146):

(11) Ouviu-se o João a abrir o portão. Quando $\mathrm{i}_{\mathrm{i} ? \mathrm{j}}$ entrou, a Luísa ${ }_{\mathrm{j}}$ pareceu-me contente.

Retomando a análise de Gonçalves (Ibid., p. 209) para as orações subordinadas completivas no PE, a autora argumenta que, sendo o sujeito de terceira pessoa não realizado foneticamente, a leitura disjunta com o sujeito da principal só será possível caso haja um tópico discursivo, através do qual o conteúdo da categoria vazia possa ser recuperado, uma situação similar à frase (11), caso contrário, a leitura co-referente estará disponível (cf. (12b)). No PB, a situação é semelhante nesses contextos:

(12) a.A - O que é que se passa com o Pedro?

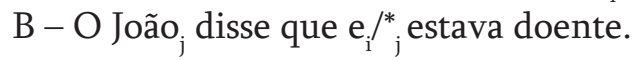
b.O João disse que $\mathrm{e}_{\mathrm{i}} / \mathrm{l}_{\mathrm{r} j}$ estava doente. 
De antemão, posso depreender, com base nas frases subordinadas analisadas, que há diferenças significativas entre o PB, por um lado, e o PE, o inglês e o francês, por outro, valendo pontuar que essas duas últimas línguas também são distintas do PE:

a) no $\mathrm{PE}$, a realização fonética do sujeito não é obrigatória na oração subordinada completiva e adverbial: sujeito nulo ou preenchido pode ser co-referente com o sujeito da oração principal ou pode receber leitura disjunta.

b) no inglês e no francês, a realização fonética do sujeito da oração subordinada completiva e adverbial é obrigatória, podendo receber leitura co-referente ou disjunta;

c) no $\mathrm{PB}$, surgem as seguintes possibilidades de análise:

c.1.a não realização fonética do sujeito da oração subordinada completiva é preferível quando ele é controlado pelo sujeito da oração principal, podendo também ser co-referente com um tópico discursivo ${ }^{9}$, sendo agramatical o controle do objeto indireto sobre a categoria vazia, ao contrário do que ocorre em PE;

c.2.a não realização fonética do sujeito da oração subordinada adverbial é preferível quando este é controlado pelo sujeito da oração principal;

c.3. a realização fonética do sujeito da oração subordinada completiva e adverbial pode implicar numa leitura co-referente ou disjunta deste com o sujeito da oração principal.

\subsection{Contextos de orações adverbiais gerundivas}

Gonçalves (1994, p. 139) observa que, nas orações gerundivas em (13), (14) e (15) do PE, do inglês e do francês, respectivamente, há controle ${ }^{10}$ obrigatório do

\footnotetext{
${ }^{9}$ Assumo nesta pesquisa com Figueiredo Silva (1996, p. 129) que a co-referência entre a categoria vazia e o sujeito da oração principal em contexto encaixado não é obrigatória, ao contrário de Ferreira (2000), haja vista a possibilidade de a categoria vazia poder ser co-referente com o sujeito da oração principal (cf. (i)), ou poder estar ligada a um tópico discursivo como em (ii):

(i) O João disse que ec. comprou um carro.

(ii) A Maria , o João disse

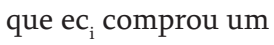
carro.

${ }^{10}$ A noção de controle a que me refiro, adotando a proposta de Lobo (2003), não está associada à noção de controle quando uma categoria vazia anafórica, nomeadamente $\mathrm{PRO}$, é requerida em determinados contextos estruturais.
} 
${ }^{11}$ Uma das propriedades elencadas por Lobo (2003, p. 315, 318) que favorecem a proposta de a categoria vazia que ocupa a posição de sujeito nas orações gerundivas periféricas corresponder a um pro e não a um PRO está relacionada ao fato de o sujeito nulo nessas orações poder ser um expletivo (cf. (i)) e poder alternar-se com sujeitos lexicais (cf. (ii)):

(i) [-] Tendo chovido durante toda a tarde, o jardim estava todo molhado.

(ii) a. Tendo [-] chegado atrasado, o Pedro não conseguiu arranjar um bom lugar.

b. Tendo o João chegado atrasado, o Pedro não conseguiu arranjar um bom lugar. sujeito da oração principal sobre o sujeito da oração subordinada quando este não é realizado foneticamente, o que implica dizer que o sujeito da oração subordinada tem de ser co-referente com o sujeito da principal, um fato que também é corroborado no PB (cf. (16)):

(13) $\mathrm{e}_{\mathrm{i}} / \mathrm{I}^{*}$ tendo telefonado, o Pedro saiu.

(14) $\mathrm{e}_{\mathrm{i}}{ }^{*}{ }_{\mathrm{j}}$ having phoned, Peter ${ }_{\mathrm{i}}$ left. "Tendo telefonado, o Pedro saiu."

(15) $\mathrm{e}_{\mathrm{i}} \mathrm{i}_{\mathrm{i}}{ }_{\mathrm{i}}$ ayant téléphoné, Pierre ${ }_{\mathrm{i}}$ est parti. "Tendo telefonado, o Pedro saiu."

(16) $\mathrm{e}_{\mathrm{i}} \mathrm{l}^{*}{ }_{\mathrm{j}}$ tendo telefonado, o Pedro ${ }_{\mathrm{i}}$ saiu.

A autora ainda verifica que o objeto da oração principal não pode controlar o sujeito da oração adjunta, mas apenas o sujeito, uma situação similar ao que ocorre no PB (cf. (20)):

(17) Português Europeu:

a. pro $_{i} /{ }_{j}{ }_{j}$ andando pelas ruas, o João ${ }_{i}$ encontrou a Maria ${ }^{11}$

(18) Inglês:

a. $\left[\right.$ pro $_{i}$ crossing the street] Jonh saw Mary $_{i}$.

$\mathrm{a}^{\prime} . *\left[\right.$ pro $_{\mathrm{j}}$ crossing the street] Jonh saw Mary $_{\mathrm{i}}$.

"Atravessando a rua, o João viu a Maria."

(BORER, 1989, p. 79 apud GONÇALVES, op. cit., p. 140)

(19) Francês:

a. $\left[\right.$ pro $_{i}$ marchant dans la rue] Jean ${ }_{i}$ a recontré Marie $_{j}$. $\mathrm{a}^{\prime} \cdot{ }^{*}\left[\right.$ pro $_{\mathrm{j}}$ marchant dans la rue] Jean $_{\mathrm{i}}$ a recontré Marie.

"Caminhando pela rua, o João reencontrou a Maria."

(20) Português Brasileiro:

a. pro $_{i}$ andando pela rua], o João viu a Maria $_{i}$.

$\mathrm{a}^{\prime} \cdot *$ pro $_{\mathrm{j}}$ andando pela rua], o João viu a Maria ${ }_{\mathrm{j}}$.

Vale ressaltar que a obrigatoriedade da coreferência do sujeito da oração subordinada com o sujeito da oração principal não é observada quando aquele é 
foneticamente realizado em línguas como o inglês e o francês, conforme ilustram os exemplos em (21) e (22), respectivamente:

(21) John $n_{i}$ being very ill, he $\mathrm{i}_{\mathrm{i}} \mathrm{j}$ couldn't sleep.

"O João estando muito doente, ele não conseguiria dormir."

(22) Pierre ${ }_{\mathrm{i}}$ ayant termine ses devoirs, $\mathrm{il}_{\mathrm{i}} / \mathrm{j}$ s'en alla.

"O Pedro terminando seus afazeres, ele foi-se."

Face aos contrastes entre as frases (21) e (22) com as de (18) e (19) em que há efeitos de controle dos sujeitos nulos das orações gerundivas adjuntas, Gonçalves (1994, p. 141) salienta:"[a] estrutura de adjunção, de facto, não deveria permitir o controle, admitindo que controle local requer c-comando.”. Assumindo que haja cisão de IP em AGRP (=ConcS") e TP nos moldes de Pollock (1989) e que a oração gerundiva está adjunta a ConcS", sendo uma projeção de Comp", a autora conclui: "ConcS" domina Espec da frase principal mas não domina Comp" adverbial" (Ibid., p. 142). Assim, o sujeito da oração principal não c-comanda, isto é, não controla o sujeito da oração gerundiva. Para a questão que se ergue relativa ao controle que se estabelece nas frases de (17) a (19) do sujeito nulo da oração gerundiva pelo sujeito da oração principal, a autora deixa em aberto: "Não é muito claro como explicar as relações de controle nas orações adverbiais com sujeito nulo. Seria necessário repensar globalmente o problema do controle e a estrutura destas orações em particular." (GONÇALVES, 1994, p. 143).

\subsection{Contextos de orações adverbiais participiais}

De forma similar às orações gerundivas, nas orações participiais, há efeitos de controle do sujeito da oração principal sobre o sujeito da oração participial quando este não é realizado foneticamente, o que implica dizer que o sujeito nulo da participial é co-referente com o sujeito da oração principal: 
(23) Português Europeu:

a. $e_{i}{ }^{*}{ }_{j}$ chegado a casa, o João ${ }_{i}$ foi-se deitar.

(24) Inglês:

a. Covered with confusion, she hurriedly left the room.

"Envolvida com a confusão, ela apressadamente saiu do quarto."

(LEECH; SVARTVIK, 1975, p. 214 apud GONÇALVES, loc. cit.)

(25) Francês:

a. $e_{i}{ }^{*}$ arrivé à la maison, Jean ${ }_{i}$ alla se coucher.

"Chegado a casa, o João foi-se deitar."

(26) Português Brasileiro:

a. $\mathrm{e}_{\mathrm{i}} /{ }^{*}{ }_{\mathrm{j}}$ Incomodado com o barulho, o João ${ }_{\mathrm{i}}$ saiu da sala.

Vale ressaltar que os efeitos de controle observados nas frases acima colocam o mesmo problema concernente à relação de c-comando, uma questão que deixo em aberto neste trabalho por extrapolar o escopo do mesmo.

\subsection{Contextos de orações adverbiais finitas}

Ao contrário do que ocorre nas orações adverbiais gerundivas e participiais (cf. (27b) e (27c)), nas orações adverbiais finitas no PE, não há necessariamente controle obrigatório do sujeito da oração principal sobre o sujeito da adverbial finita (cf. (27a)):

(27) a. Quando $\mathrm{e}_{\mathrm{i}} /$ ??j chega atrasado, o director ${ }_{\mathrm{i}}$ fica mal humorado.

b.Chegando $\mathrm{e}_{\mathrm{i}}{ }^{*}{ }_{\mathrm{j}}$ atrasado, o director ${ }_{\mathrm{i}}$ fica mal humorado.

c. Chegado $\mathrm{e}_{\mathrm{i}} /{ }_{\mathrm{j}}$ a casa, o director ${ }_{\mathrm{i}}$ tirou a gravata.

No inglês e no francês, ao contrário do PE, é obrigatória a realização fonética do sujeito nos tipos de orações acima, um contraste que as opõe às adjuntas gerundivas e participiais. Nessas línguas, o sujeito da oração adverbial finita pode ter leitura co-referente ou disjunta: 
(28) a. ${ }^{*}$ When $\mathrm{e}_{\mathrm{i}} / \mathrm{j}$ arrives late, the director ${ }_{\mathrm{i}}$ is angry.

a'. When he ${ }_{i} /$ arrives late, the director ${ }_{i}$ is angry.

"Quando ele chega tarde, o diretor fica zangado."

b. *Quand $\mathrm{e}_{\mathrm{i}} / \mathrm{j}$ arrive tard, le directeur $\mathrm{r}_{\mathrm{i}}$ est en colère.

b'. Quand $\mathrm{il}_{\mathrm{i}} / \mathrm{j}$ arrive tard, le directeur $\mathrm{r}_{\mathrm{i}}$ est en colère.

"Quando ele chega tarde, o diretor fica zangado."

Comparando as estruturas frásicas das três línguas acima com as estruturas do PB abaixo (cf. (29) e (30)), observo que os sujeitos podem ser nulos ou preenchidos, o que permite, de alguma maneira, certa similaridade com o PE, o inglês e o francês:

a) a não realização fonética do sujeito da oração adverbial é preferível quando ele é coreferente com o sujeito da oração principal, estando a leitura disjunta reservada aos casos em que é possível haver um antecedente no domínio do discurso com o qual a categoria vazia liga-se:

(29) Quando e $e_{i} /$ ??j entrou, o João teve um susto.

b) a realização fonética do sujeito da oração adverbial permite que este possua leitura coreferente ou disjunta:

(30) Quando ele $\mathrm{i}_{\mathrm{i} j}$ chega atrasado, o director ${ }_{\mathrm{i}}$ fica mal humorado.

Partindo das estruturas subordinadas gerundivas, participiais e adverbiais finitas, a partir das quais realizei uma análise descritiva entre o $\mathrm{PE}$, o inglês, o francês e o $\mathrm{PB}$, elenco as seguintes conclusões:

a) Em estruturas gerundivas e participiais nas quatro línguas em estudo, há controle obrigatório do sujeito não realizado foneticamente da oração subordinada pelo sujeito da oração principal; 
b) Em estruturas adverbiais finitas, tem-se uma análise não-unificada:

b.1 No PE, o sujeito nulo da oração subordinada pode receber leitura co-referente ou disjunta do sujeito da oração principal, sendo a primeira leitura preferencial consoante ao que acontece no PB;

b.2 No inglês e no francês, a realização fonética do sujeito da oração subordinada é obrigatória, podendo este receber leitura co-referente ou disjunta do sujeito da oração principal;

b.3 No PB, quando a realização fonética do sujeito da oração subordinada é possível, a leitura co-referente ou disjunta com o sujeito da oração principal está disponível tal como acontece no inglês e no francês.

\subsection{Contextos de pergunta-resposta com focalização do sujeito}

Um dos contextos obrigatórios para a realização fonética do sujeito nas línguas pro-drop e não-prodrop correspondem àqueles quando o sujeito está sendo focalizado na pergunta, sendo este a informação nova que se quer veicular. A distinção substancial entre essas línguas nesses contextos diz respeito à posição dos sujeitos focalizados; nas primeiras, como é o caso do PE e do italiano: o sujeito aparece posposto ao verbo, uma posição suscetível a hospedar constituintes focalizados consoante o que está previsto pela estrutura informacional, ao passo que, nas segundas, como o inglês, sujeitos focalizados aparecem em posição pré-verbal, à semelhança do $\mathrm{PB}$, o que distingue ambas as línguas das línguas de sujeito nulo prototípicas. No caso do francês, Gonçalves (1994) argumenta que, não dispondo essa língua da elipse do VP, as únicas opções de o DP sujeito aparecer focalizado na resposta dá-se quando ele aparece sozinho (cf. (41f)) ou 
quando é usada a estratégia de focalização com o verbo ser (cf. (41g)).

Vejam-se, agora, os seguintes pares perguntaresposta com focalização do sujeito no PE e no italiano por um lado (cf. (31) e (32)), e no inglês, no francês e no $\mathrm{PB}$, por outro (cf. (40) a (42)):

(31) Falante A: -Quem comeu o bolo?

Falante B - a) ${ }^{*}$ Comi.

b) Comi eu.

c) Comi-o eu.

d) ?*Eu comi (não sei quem comeu mais...)

e) Fui eu.

f) ${ }^{*}$ Fui.

g) ${ }^{*} \mathrm{Eu}$ fui.

(32) A - Chi ha mangiato la cioccolata?

"Quem tem comido o chocolate?/ "Quem comeu o chocolate?"

$\mathrm{B}-\mathrm{a} .{ }^{*} \mathrm{~L}$ 'ho mangiata.

O tenho comido./ "Comi-o."

${ }^{12}$ Os grifos são da autora da citação.

b. L'ho mangiata io.

O tenho comido eu./ "Comi-o eu."

c. ?*'Io l'ho mangiata.

Eu tenho comido./ "Eu comi-o."

d. Sono stato io.

Sou estado eu./ "Fui eu."

e. *Sono stato.

Sou estado./ "Fui."

f. * Io sono stato.

Eu sou estado./ "Eu fui."

(GONÇAVES, 1994, p. 150-151) 12 $^{12}$

(40) A - Who ate the cake?

B - a. John did.

b. *Did John.

c. *John ate.

d. *Ate John.

e. It was John. 
(41) A - Qui a mangé le gâteau?

$B-a$. Jean a.

b. *A Jean.

c. *Jean a mangé.

d. *A mangé Jean.

e. ?*Jean l'a mangé.

f. Jean.

g. C'est Jean (qui l'a mangé).

h. 'L'a mangé Jean.

${ }^{13}$ Ao contrário do PE, o sujeito pré-verbal nessa construção não se encontra submetido à restrição de possuir necessariamente leitura contrastiva, valendo pontuar que a mesma pode estar presente dependendo do contexto pragmático como apresentado em (i) a seguir: (i) A - Quem comeu o bolo?

B - Eu comi (não sei quem comeu mais...).

(42) A - Quem comeu o bolo?
B - a) *Comi.
b) *Comi eu.
c) *Comi-o eu.
d) Eu comi. ${ }^{13}$
e) Fui eu.
f) *Fui.
g) *Eu fui.

Partindo da descrição dos contextos estruturais acima apresentados, fica evidente que no PE e no italiano, sujeitos focalizados só aparecem em posição pré-verbal quando submetidos à restrição de receberem obrigatoriamente leitura contrastiva, não correspondendo, portanto, a "verdadeiros" focos informacionais (cf. (31d) do PE, por exemplo) em virtude de haver "outros candidatos possíveis como resposta à mesma pergunta" (GONÇALVES, 1994, p. 153). Contrariamente, no inglês, no francês e no PB, essa restrição inexiste: sujeitos focalizados não estão em posição pós-verbal, haja vista a inversão estar restrita a contextos inacusativos (cf. KATO, 1999, SILVA, 2004). $A$ única diferença existente nesses contextos entre o $\mathrm{PB}$, por um lado, o inglês e o francês, por outro, é que estas exigem a leitura indefinida do DP pós-verbal (cf. (43)), ao passo que aquela permite essa leitura, o que a assemelha ao PE (cf. (44)): 
(43) a. There arrived a man/ *the man/ *every man. Inglês "Chegou um homem/ *o homem/ *todo homem." b.Il est arrivé un homme/ ${ }^{*}$ ' homme. Francês "Chegou um homem/ *o homem."

(ALEXIADOU; ANAGNOSTOPOULOU, 1998, p. 512)

(44) a. Fechou muitas fábricas. (OKPE OKPB)

b. Chegou as cadeiras. (OKPE OKPB)

(COSTA, 2001, p. 8)

De mais a mais, podem ser depreendidos os seguintes resultados:

a. A realização fonética do sujeito é obrigatória em resposta a uma pergunta com focalização do sujeito no PE, no francês, no inglês e no PB;

b. Sujeitos focalizados no PE e no italiano sempre ocorrem em posição pós-verbal, exceto nos casos em que recebem leitura contrastiva;

c. Sujeitos focalizados no inglês e no PB sempre ocorrem em posição pré-verbal, exceto nos casos em que é utilizada a estratégia de focalização com o verbo ser, uma opção também prevista no francês.

\subsection{Contextos de respostas a interrogativas QU- que não incidem sobre o sujeito}

Analisando as estruturas de interrogativas QUparciais com focalização de um constituinte distinto do sujeito, Gonçalves (1994) observa que a não realização fonética do sujeito é obrigatória no $\mathrm{PE}$, conforme ilustra o seguinte exemplo:

(45) A: - Quem é que o João encontrou no cinema?

B: - a.O Pedro.

b. ?Foi o Pedro.

c. Encontrou o Pedro.

d. ${ }^{*}$ Ele encontrou o Pedro. 
A explicação formulada pela autora para explicar a agramaticalidade da frase em (45d) resulta no fato de que só sujeitos focalizados podem ser realizados foneticamente pelo fato de corresponderem à informação nova. Segundo a autora, nesses exemplos, os sujeitos não correspondem ao foco informacional, mas ao tópico discursivo, ou seja, à informação dada já que seu referente foi previamente mencionado no domínio do discurso que em (45) corresponde ao DP o João já presente na pergunta.

Contrariamente ao $\mathrm{PE}$, o inglês e o francês não permitem sujeitos não realizados foneticamente, mas aceitam marginalmente a realização fonética destes:

(46) A - Who did John meet yesterday?

B - a. $\left.{ }^{*}{ }^{*} \mathrm{He}\right)$ did Peter.

b. ${ }^{*}$ Met Peter.

c. ?He met Peter.

d. Peter.

e. ?It was Peter.

(47) A - Qui est-ce que Jean a rencontré hier?

B - a. * ${ }^{*}$ Il $)$ a Pierre.

b. ${ }^{*}$ A rencontré Pierre.

c. ??Il a rencontré Pierre.

d. Pierre.

e. C'est Pierre (qu'il a rencontré).

Observando as frases, a seguir, do $\mathrm{PB}$, verifico que há um comportamento distinto do $\mathrm{PE}$, do inglês e do francês: os sujeitos podem ser realizados foneticamente ou não, sendo preferencial a sua realização (cf. (48d)):

(48) A: - Quem o João encontrou no cinema?

B: - a.O Pedro.

b. ?Foi o Pedro.

c.?Encontrou o Pedro.

d. Ele encontrou o Pedro. 
Assim, face às interrogativas QU- com focalização de um constituinte distinto do sujeito analisadas nesta seção, resumo as seguintes conclusões:

a) a estratégia de focalização do constituinte pelo verbo ser está disponível em todas as línguas;

b) a não realização fonética do sujeito nas respostas é obrigatória em $\mathrm{PE}$;

c) a realizaçãofonética do sujeitoémarginalmente aceitável no inglês e no francês;

d) a realização fonética do sujeito nas respostas é preferencial no PB e marginalmente aceitável quando trata-se de uma categoria vazia.

\subsection{Contextos de respostas a interrogativas totais}

Gonçalves também verifica que a não realização fonética do sujeito é obrigatória no PE (cf. (49)) quando ele ocorre em respostas a interrogativas totais (ou interrogativas sim/não), ao contrário do inglês e do francês ${ }^{14}$ (cf. (50) e (51)):

(49) A - O João viu o Pedro?

$\mathrm{B}-\left({ }^{*}\right.$ Ele $)$ viu.

(50) A - Has John seen Peter?

B - Yes, ${ }^{*}($ he) has.

(51) A - Jean a-t-il vu Pierre?

B - Oui, *(il) l'a vu.

Novamente, um caso curioso ergue-se no PB: nos contextos interrogativos acima, o sujeito pode ser realizado foneticamente ou não. ${ }^{15}$ Ao contrário do que acontece nas interrogativas QU- parciais com focalização de um constituinte distinto do sujeito, é preferível a não realização do sujeito. Nesse caso, semelhantemente ao PE e ao inglês, há elipse do VP nas respostas, conforme ilustra a frase (52a), uma opção não prevista em línguas como o francês (cf. (53)) e o italiano (cf.(54)), segundo verificado por Gonçalves (1994, p. 190) ${ }^{16}$ :

${ }^{14}$ Gonçalves (1994) observa, ao contrário do PE, que no francês, no inglês, no italiano e no espanhol,

respostas afirmativas a interrogativas totais devem possuir as partículas afirmativas oui, yes, sì e sí, respectivamente. Já, em se tratando de respostas negativas, elas podem ser dadas ou com a partícula negativa, ou com advérbios negativos nas cinco línguas acima referidas. Para uma descrição dessas respostas, sugiro ao leitor conferir a pesquisa dessa autora.

${ }^{15}$ Magalhães e Santos (2006) observam que as respostas verbais nos contextos das interrogativas em análise correspondem a um contexto de manutenção do sujeito nulo não só no PE, por exemplo, mas também no PB, conforme evidenciam os dados da gramática adulta e os dados de aquisição. Para maiores detalhes dessa proposta, sugiro ao leitor consultar o referido trabalho.

${ }^{16}$ Os grifos são da autora. 
(52) A - O João viu o Pedro?

B - a. Viu.

b. ?Ele viu.

(53) A - As-tu vu Jean?

B - Oui, je l'ai vu.

- Non, je ne l'ai pas vu.

- ${ }^{*} \mathrm{Ai}(\mathrm{vu})$.

- *oui, j’ai (vu)

- ??/?*Je l'ai vu.

(54) A - Hai visto Giovanni?

B - Sì, l'ho visto.

- No, non l'ho visto.

- *Ho visto.

- $\mathrm{Si},{ }^{*}\left(\mathrm{l}^{\prime}\right)$ ho visto.

- ?*L'ho visto.

Partindo dos contextos descritos acima, elenco, portanto, as seguintes conclusões:

a. a não realização fonética do sujeito no PE é obrigatória nas respostas quando o verbo está presente;

b. a realização fonética do sujeito no inglês e no francês é obrigatória nas respostas quando o verbo está presente;

c. a realização fonética do sujeito pode dar-se ou não no $\mathrm{PB}$, sendo preferencial o uso da categoria vazia nas respostas quando o verbo está presente.

d. O PE, o inglês e o PB têm elipse do VP nas respostas, ao contrário do que ocorre no francês e no italiano.

\section{Conclusão}

Centrando minha atenção no Parâmetro do Sujeito Nulo, é plausível considerar que a hipótese da binaridade desse parâmetro pode ser refutada, tendo em vista o caráter semi-pro-drop do $\mathrm{PB}$ que se aproxima do 
$\mathrm{PE}$, uma língua de sujeito nulo prototípica, ao mesmo tempo, que se distancia desta por compartilhar algumas propriedades com línguas não-pro-drop, como o inglês e o francês.

Classificar o PB como uma língua semi-pro-drop ganha, portanto, suporte empírico quando observados os contextos estruturais descritos neste artigo. Em contextos de orações coordenadas, gerundivas e participiais, sendo o DP sujeito foneticamente nulo, a leitura co-referente do sujeito da oração coordenada ou subordinada com o sujeito da oração coordenante ou principal, respectivamente, é obrigatória nessa língua, no PE, no inglês e no francês. Contudo, as assimetrias entre essas línguas constatam-se nos seguintes casos:

a) em orações coordenadas, a realização fonética do sujeito no PE é obrigatória quando a referência é disjunta, não havendo, portanto, co-referência obrigatória do sujeito da oração coordenante com o sujeito da oração coordenada, ao passo que no inglês, no francês e no $\mathrm{PB}$, o sujeito realizado foneticamente na oração coordenada pode ou ser co-referente com o sujeito da oração coordenante, ou receber leitura disjunta;

b) Em orações subordinadas completivas e adverbiais, a realização fonética do sujeito é obrigatória no inglês e no francês, estando disponíveis as leituras co-referente e disjunta do sujeito da subordinada com o da principal, ao contrário do $\mathrm{PB}$ e do $\mathrm{PE}$;

c) Em contextos de pergunta-resposta com focalização do sujeito, é obrigatória no $P B$, no inglês, no PE e no italiano a realização fonética do sujeito nas respostas, contudo uma assimetria se observa entre as duas primeiras línguas por um lado, e as duas últimas, por outro: enquanto nas primeiras, sujeitos focalizados sempre aparecem em posição 
pré-verbal, nas segundas sempre aparecem em posição pós-verbal, salvo os casos de não corresponderem a focos informacionais;

d) Em contextos de respostas a interrogativas QUque não incidem sobre o sujeito, é obrigatória a não realização fonética do sujeito no $\mathrm{PE}$, ao contrário do inglês e do francês que aceitam marginalmente a realização fonética. No PB, essa marginalidade observada nessas duas últimas línguas inexiste: a realização fonética do sujeito nas respostas é preferível nessa língua e marginalmente aceitável quando trata-se de uma categoria vazia;

e) Em contextos de respostas a interrogativas totais, é obrigatória a não realização fonética do sujeito no $\mathrm{PE}$, ao contrário do inglês e do francês. Já no $\mathrm{PB}$, o sujeito pode ser realizado foneticamente ou não, sendo preferível o uso de uma categoria vazia.

Em suma, a análise comparativa realizada entre o $\mathrm{PB}$, o PE, o inglês e o francês, concernente ao licenciamento de sujeitos nulos e plenos e à referência dos mesmos nos contextos estruturais analisados, atesta o caráter semi-pro-drop do PB: por um lado, essa língua compartilha propriedades com as demais línguas referidas; por outro lado, em alguns contextos estruturais, aproxima-se do PE e, em outros, aproxima-se do inglês e do francês, tendo, em alguns casos, propriedades que lhe são peculiares, distanciando-se dessas três línguas. 


\section{Referências}

ALEXIADOU, A.; ANAGNOSTOPOULOU, E. Parametrizing AGR: word order, V-movement and EPP-checking. Natural Language and Linguistic Theory, n. 16, p. 491-539, 1998.

CHOMSKY, N. Lectures on government and binding. Dordrecht: Foris Publications, 1981.

COELHO, I. L. et. al. Ordem VS e sujeito nulo em PE e PB. In: 2o COLÓQUIO DO PROJETO PE/ PB. Paper..., Universidade do Ceará, Fortaleza, 2001.

COSTA, J. Postverbal subjects and agreement in unaccusative contexts in European Portuguese. The Linguistic Review, v. 18, p. 1-17, 2001.

COSTA, J.; GALVES, C. External subjects in two varieties of Portuguese evidence for a non-unified analysis. In: BEYSSADE, C. et al. Romance languages and linguistic theory 2000, Utrecht, 30 November-2 December. v. 232. Amsterdam; Philadelphia : John Benjamins Publishing Company, 2002. p. 109-125.

DUARTE, M. E. L. The loss of the 'avoid pronoum' principle in Brazilian Portuguese. In: KATO, M. A.; NEGRÃO, E. V. (Eds.). Brazilian Portuguese and the null subject parameter. Madrid : Iberoamericana, 2000, p. 17-36.

FERREIRA, M. B. Argumentos nulos em português brasileiro. 2000. Dissertação (Mestrado em Linguística) - Universidade Estadual de Campinas, Campinas.

FIGUEIREDO SILVA, M. C. A posição sujeito no português brasileiro: frases finitas e infinitivas. Campinas: Ed. da UNICAMP, 1996.

GALVES, C. C. Ensaios sobre as gramáticas do português. Campinas, SP: Ed. da UNICAMP, 2001. 
GONÇALVES, M. F. H. S. L. Para uma redefinição do parâmetro do sujeito nulo. 1994. Dissertação (Mestrado em Lingüística Portuguesa Descritiva) - Faculdade de Letras da Universidade de Lisboa, Lisboa.

HUANG, J. C. T. Pro-drop in Chinese: a generalized control theory. In: JAEGGLI, O.; SAFIR, K. J. The null subject parameter. Dordrecht, London: Kluwer Academic Publishers. p. 185-214, 1989.

KATO, M. A. A restrição de monoargumentalidade da ordem VS no português do Brasil. Fórum Lingüístico. Florianópolis, Pós-graduação em Lingüística, UFSC, 1999. p. 1-21. (no prelo)

LOBO, M. Aspectos da sintaxe das orações subordinadas adverbiais do português. Tese (Doutorado em Lingüística) Universidade Nova de Lisboa, 2003.

MAGALHÃES, T. M. V.; SANTOS, A. L. As respostas verbais e a freqüência de sujeito nulo na aquisição do português brasileiro e português europeu. Letras de Hoje, 1, no 1, p. 179193. Porto Alegre: EdiPUCRS, 2006.

MATOS, G. Estruturas de coordenação. In: MATEUS, M. H. M. et al. Gramática da língua portuguesa. 5. ed. rev. aum. Lisboa : Caminho, 2003, p. 549-592.

POLLOCK, J. Verb movement, universal grammar, and the structure of IP. Linguistic Inquiry, v. 20, n. 3, p. 365-424, 1989.

RIZZI, L. The new comparative syntax: principles and parameters of universal grammar. In: 10th ADVANCED COURSE "LANGUAGE AND COGNITION". Foundation Archives Jean Piaget, Geneva, p. 1-20, October 10, 1988.

RIZZI, L. A Parametric Approach to Comparative Syntax: Properties on the Pronominal System. HAEGEMAN, Liliane (ed.). The New Comparative Syntax. London, New York: Longman, 1997. p. 268-285. 
SILVA, C. R. T. As Implicações da Natureza de AGR para

a Ordem VS: Um Estudo Comparativo entre o Português

Brasileiro e o Português Europeu. 2004. Tese (Doutorado em

Lingüística) - Universidade Federal de Alagoas, Maceió. 